\title{
DISPOSITIVOS DE REGULAÇÃO CONSERVADORA, CURRÍCULO E TRABALHO DOCENTE*
}

\author{
Jarbas Santos Vieira* \\ Álvaro Moreira Hypólito ${ }^{* * *}$ \\ Bárbara Gonçalves Vaz Duarte ${ }^{* * *}$
}

\begin{abstract}
RESUMO: Neste artigo discutimos dispositivos de controle, como regulação conservadora, e suas interferências tanto no processo de trabalho de professoras em início de carreira quanto na fabricação de suas identidades profissionais. A análise aqui apresentada é fruto de uma pesquisa realizada com professoras que atuam entre a $1^{\text {a }}$ e a $4^{a}$ série do ensino fundamental em escolas públicas, com menos de três anos de magistério e sem experiência anterior de trabalho efetivo em sala de aula. É sobre as professoras em início de carreira que se produz um conjunto de práticas (discursos) que tem como função regular suas práticas e decisóes, estabelecendo o quadro das condutas consideradas legítimas para que se efetive o processo educativo. Os efeitos dessa regulação agem sobre o processo de trabalho docente e sobre os processos de significação nele produzidos, estabelecendo uma representação do que vêm a ser a docência e sua identidade, tratando assim de ressignificar as práticas educativas.
\end{abstract}

Palavras-chave: Trabalho docente. Dispositivos de controle. Currículo. Identidade.

* Este artigo, agora revisado e ampliado, foi apresentado no GT-12 - Currículo, na 29a Reunião Anual da ANPEd, em 2006. É resultado de estudos vinculados a projeto de pesquisa apoiado pelo CNPq.

** Doutor em Educação e professor da Universidade Federal de Pelotas (UfPel). E-mail: jarbas@ufpel.edu.br

*** Doutor em Educação e professor da UfPel. E-mail: alvaro.hypolito@gmail.com

**** Mestre em Educação e professora do Centro Federal de Educação Tecnológica (CEFET-RS). E-mail: bgvduarte@gmail.com

Educ. Soc., Campinas, vol. 30, n. 106, p. 221-237, jan./abr. 2009

Disponível em <http://www.cedes.unicamp.br> 


\section{CONSERVATIVE REgUlation DEVICES, CURRICULUM AND TEACHING}

ABSTRACT: This paper discusses control devices as a conservative regulation and how they interfere both in the teaching process of beginning teachers and in their professional identity construction. It analyses data from a study with public elementary school beginning teachers who have taught for three years without previous teaching experience. Many practices (discourses) are produced to regulate and constrain beginning teachers' judgment in terms of practices and decisions, establishing legitimate professional behaviors. This regulation - built through a set of control devices - acts on the teaching process and on its meaning processes, creating a representation about what teachers and their identity should be, thus re-signifying their practices.

Key words: Teacher's work. Control devices. Curriculum. Identity.

\section{Introdução}

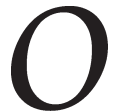

s estudos sobre o currículo e suas relações com a organização escolar e o processo de trabalho docente apontam para a existência de dispositivos de controle que, atuando no interior das escolas, impedem ou retardam, de alguma forma, as mudanças educacionais, produzindo efeitos sobre o desempenho e a identidade do professorado.

Neste artigo discutimos os dispositivos de controle conservador e suas interferências no processo de trabalho de professoras em início de carreira, algo que parece fundamental para a conformação do que os docentes se tornarão. Isso deve ser cotejado com as formas de governo da conduta derivadas da onda de conservadorismo para o qual o professorado é "capturado", muitas vezes trafegando entre o tradicional neoconservador - e o hipermoderno - neoliberal.

A análise aqui apresentada é fruto de uma pesquisa ${ }^{1}$ realizada com oito professoras que atuam entre a $1^{\text {a }}$ e a $4^{a}$ série do ensino fundamental em escolas públicas municipais da cidade de Pelotas, Rio Grande do Sul, com menos de três anos de magistério e sem experiência anterior de trabalho efetivo (contratação ou nomeação) em sala de aula, com exceção de estágios. Eram professoras recém-formadas em cursos de licenciatura, especificamente de Pedagogia. 
Privilegiamos um recorte muito específico sobre as formas de controle do professorado, pois sabemos que este grupo é o que mais sente os efeitos dos dispositivos de controle produzidos nas escolas ao sofrer o impacto inicial da carreira, quando o currículo entra em ação. Por isso entendemos que esse grupo dá mais visibilidade aos efeitos desses dispositivos. É sobre os professores e as professoras em início de carreira que se produz um conjunto de práticas (discursos) que tem como função normalizá-los(as), isto é, regular suas práticas e decisões, estabelecendo o quadro das condutas consideradas legítimas para que se efetive o processo educativo.

Os efeitos dessa regulação, estabelecida por intermédio de práticas discursivas assentadas na tradição e nos discursos que dela derivam, agem sobre o processo de trabalho docente e sobre os processos de significação nele produzidos, estabelecendo uma representação do que vêm a ser a docência e sua identidade, tratando assim de ressignificar sua prática, positiva ou negativamente.

Esses dispositivos, construindo controles sobre aquilo que os professores e as professoras fazem em sala de aula e na escola, por extensão, asseguram o exercício do poder institucional assentado nas normas legais (normatização), que, amiúde, reforçam e multiplicam o discurso da tradição e da burocracia intelectual no sistema de ensino, algo próximo daquilo que Goodson (1995) define como currículo escrito - sem ignorar o impacto das editoras e da mídia televisiva.

Da mesma forma, o conjunto de documentos político-pedagógicos, tais como os Parâmetros Curriculares Nacionais (PCN), acaba contribuindo para controlar o saber-fazer docente, funcionando para determinar o que deve e pode ser feito no processo de trabalho. O resultado de tal processo constitui aquilo que a professora é, aquilo que faz e deixa de fazer.

Sobre o professorado, principalmente aquele em início de carreira, impõe-se um modo de ser e de fazer educação, em que são estabelecidos os horizontes possíveis de ação e de intervenção docente, geralmente suturado pela força da tradição e da burocracia escolar, institucional, estatal, tornando a educação aquilo que ela é hoje; tornando o professorado rapidamente normalizado.

Analisamos assim os dispositivos de regulação da prática docente a fim de identificá-los, de compreender seus discursos, seus mecanismos 
heurísticos, sua matéria-prima institucional, burocrática, hierárquica e imaginária (a tradição), levando em conta seus efeitos de controle sobre o trabalho docente e o professorado. Construímos uma analítica do seu funcionamento para compreender o que ocorre com professores e professoras após os primeiros anos de trabalho.

Essa analítica possibilita entender como funcionam os mecanismos de permissão e de impedimento das práticas de trabalho do professorado em início de carreira; o grau de decisão permitido sobre seu processo de trabalho, seu fazer curricular, e os efeitos e significados que isso tem sobre suas expectativas e identidade profissionais.

Nesse esforço examinamos as relações das professoras em início de carreira, ${ }^{2}$ suas decisões pedagógicas em sua classe e com os diferentes segmentos da escola - mediaçôes experimentadas no interior do trabalho docente e as relações sociais educacionais vividas em cada escola.

Antes, porém, de passar às discussóes propostas neste artigo, gostaríamos de chamar a atenção do leitor a respeito de aspectos que, se não esclarecidos, podem indicar debilidades do trabalho: (i) falta de discussão sobre a autonomia docente e possibilidades de fugas e resistências nas práticas docentes nas escolas; (ii) a ausência de uma análise das relações de gênero; (iii) a falta de discussão sobre a organização e as condiçõos de trabalho que conduzem à precariedade do ofício docente. Em outras situaçôes nas quais tivemos oportunidade de apresentar nossos argumentos, questionamentos sobre tais aspectos foram levantados.

Em primeiro lugar, é preciso considerar que a pesquisa que gerou este artigo teve um objetivo muito particular: discutir como a tradição pode funcionar no contexto escolar como dispositivo de controle, e não a busca de uma análise das formas transgressoras a esse controle. Nos dados coletados na pesquisa há indicaçôes de fugas e comportamentos contestadores aos dispositivos de controle, no entanto tais dimensões, além de desviar o foco da análise aqui desenvolvida, seriam uma empreitada que demandaria outro texto. Em segundo lugar, algo semelhante ocorre a respeito das relações de gênero. Seria possível uma análise das relações de gênero, mas estas não foram o foco do estudo e, por isso, não foram problematizadas na coleta de dados. Por fim, em terceiro lugar, nossas preocupaçôes centram-se nos mecanismos que operam nas relações político-pedagógicas entre docentes, procurando entender 
como professoras com ingresso recente na carreira são trazidas à tradição conservadora por meio de dispositivos de controle postos em ação no processo de trabalho. Importante reter é que estamos mais interessados em compreender como esses dispositivos operam para essas professoras e menos focados na análise e descrição da precariedade do trabalho, que, sabemos, se aprofunda a cada dia. ${ }^{3}$

$\mathrm{Na}$ seção seguinte caracterizamos o que compreendemos como dispositivos; seu funcionamento e seus efeitos específicos sobre o professorado em início de carreira.

\section{Dispositivos de controle}

Dispositivos são ações (discursos) que interferem na disposição das relações sociais, prescrevendo, ordenando, normalizando as formas e os conteúdos de como essas relaçôes devem ocorrer, ou serem estabelecidas e/ou mantidas. Um dispositivo é então uma espécie de norma prática, de preceito que atua nas diferentes partes de um aparelho social, desempenhando uma função especial com vistas a um fim determinado. Essas açôes funcionam de forma pouco coordenada no seio das relaçôes institucionais, buscando a prevenção/interrupção de desvios e/ou rupturas do grupo social.

Os dispositivos integram - ou estão conectados a - os aparelhos institucionais, constituindo-se como uma prática de intervenção nas relaçôes de poder nesses aparelhos; servindo como instrumento capaz de decidir ou conjurar problemas; formando uma espécie de unidade momentânea de combate contra a iminência da desagregação do grupo - os dispositivos somente são acionados para prevenir açôes de ruptura do grupo social, tentando proteger unidades/relações estabelecidas contra o uso indevido ou a sobrecarga social (política) (Deleuze, 1990), assim garantindo a segurança pública em situaçōes consideradas anormais, fora dos padrões estabelecidos pela instituição e por sua tradição imaginada.

Os dispositivos ocorrem sob variados formatos, e sua duração permanece o tempo que for conveniente para manter, garantir, impedir uma ação desviante. Portanto, seus efeitos somente podem ser sentidos quando postos em ação, prescindindo, a princípio, da necessidade de regulação legal, embora possam se valer de normas preestabelecidas: as leis e as hierarquias de comando por elas estabelecidas dentro e entre instituições. 
Entretanto, os dispositivos, por sua natureza "um tanto sísmica" (Deleuze, 1990), não garantem, de antemão, a coesão do grupo social nos aparelhos institucionais, pois, como alerta Deleuze:

O dispositivo é uma espécie de novelo ou meada, um conjunto multilinear. É composto por linhas de natureza diferente e essas linhas do dispositivo não abarcam nem delimitam sistemas homogêneos por sua própria conta (o objeto, o sujeito, a linguagem), mas seguem direções diferentes, formam processos sempre em desequilíbrio, e essas linhas tanto se aproximam como se afastam umas das outras. Cada [uma] está quebrada e submetida a variações de direção (bifurcada, enforquilhada), submetida a derivaçôes. Os objetos visíveis, as enunciaçoes formuláveis, as forças em exercício, os sujeitos numa determinada posição são como que vetores ou tensores. (apud Vieira, Hypólito \& Duarte, 2006, p. 3 e 4; grifos dos autores)

Nessa medida, os dispositivos, ao mesmo tempo em que buscam produzir sujeitos conformados à tradição da instituição, também podem provocar (fabricar) fissuras, fraturas irremediáveis (Deleuze, 1990), podendo gerar respostas impensadas, linhas intempestivas que vão desde a exclusão do desviante até o aprofundamento da ruptura do grupo, embora a conformabilidade à norma, o reenvio do desviante, seja o objetivo primeiro.

Os dispositivos de controle, acionados pelas escolas e pelos currículos, funcionam explicitamente por meio de normas burocráticas institucionais para garantir práticas amplamente aceitas como adequadas ao processo de ensino. Entretanto, sua eficácia (produtividade) somente pode ser obtida por intermédio de mecanismos específicos que geralmente apelam à tradição imaginada (Hall, 2001) do local de trabalho.

\section{A investigação dos dispositivos de controle}

Nesta seção, apresentamos o funcionamento e os significados dos dispositivos de controle acionados para regular/normalizar o processo de trabalho das professoras em início de carreira.

Entretanto, num primeiro momento, é preciso dizer que, se os dispositivos de controle se ancoram nas leis e em normas burocráticas, seu discurso de convencimento também apela para os usos e costumes 
rotineiros de cada escola. Independentemente da retórica que utilizam, tais dispositivos visam à coesão do grupo, à estabilidade das relações de poder e ao impedimento de inovações pedagógicas, aprofundando a perda de autonomia docente sobre o processo de trabalho.

Os dispositivos acionados para regular/normalizar a prática pedagógica das professoras em início de carreira estabelecem controles cada vez mais rígidos sobre o processo de trabalho docente, na garantia de que o novo integrante do grupo não destoe das formas de trabalho ali consagradas pela tradição. Esses dispositivos concorrem para que possa ser estabelecido o quadro das condutas considerado legítimo para que se efetive o processo educativo na escola.

Os dispositivos de controle efetivam-se por meio das relações sociais internas à escola marcadas por discursos de apelo à tradição. Seus efeitos servem para sinalizar a prática desejada na escola e quais os riscos que devem ser evitados: o rompimento da coesão do grupo de docentes e a não-aprendizagem de alunos e alunas, que podem ferir as rotinas do local de trabalho e alterar as relações de poder ali consagradas.

Com efeito, ao ver suas iniciativas de inovação impedidas, a professora recém-chegada à escola experimenta uma radical restrição ao seu processo de trabalho, podendo conformar-se à experiência que já encontrou ali constituída:

(...) eu tenho que aprender com os meus colegas. Acho que agora do jeito que estou vendo as coisas, eu acho que elas estão certas. Eu acho que já estou me bandeando para o outro lado. Eu acho que elas estão certas, porque eu, na minha visão, não que professora tenha que andar carregada de material, mas eu tenho uma colega que todos os dias ela chega só com a bolsa dela, todos os dias ela sai do colégio com a bolsa, não que tenha que levar material para casa. (...) a bolsa dela mostra como é o trabalho dela. Ela senta na cadeira e diz: "abram o livro na página tal”, e fica quase toda a manhã sentada na cadeira, não se envolve mais com os alunos. Hoje eu presumo que é ela que está certa, sofrer como eu sofri agora com os pais... Acho que tu não podes querer ousar... (Professora J).

Porque como disse outra professora outro dia: "esse negócio de escola pública é como tu nadares de poncho contra a maré". Às vezes é um pouco tu sozinha. É um monte de coisas juntas, e a escola não vai resolver todos os problemas; a professora na sala de aula não vai. E eu entrei muito com essa ideia de..., de repente..., e quando tu vês que tu não consegues, tu começas a ficar muito angustiada... (Professora S) 
Nestes discursos, seja pelo exemplo recebido da colega, seja pelo sentimento de impotência experimentado solitariamente, o controle docente sobre seu processo de trabalho fica seriamente afetado, restando uma dimensão pouco reflexiva do ato educativo. Limita-se o trabalho docente à aprendizagem da disciplina e da autodisciplina exigidas pela escola e pelos aparatos burocráticos ali instalados. A professora torna-se, "com autonomia", uma trabalhadora disciplinada (controlada) segundo a tradição encontrada na escola.

Aqui a tradição imaginada cumpre seu papel de controle, valendo-se da repetição (das experiências, das leis: as leis sempre são lembradas), e funcionando como uma crença que tem o efeito de doutrinação simbólica, produzindo mecanismos que retiram a autonomia intelectual do professorado. Em nome da tradição - e da coesão - do grupo, constitui-se então um modelo de controle talvez mais poderoso e mais insidioso sobre o trabalho docente, confundindo as tentativas de inovação das professoras com sua falta de experiência, ingenuidade, incompetência ou adversidades culturais. Nesse processo, prevalece a ideia de magistério como uma vocação (e sacerdócio) que nem todos possuem, mas que devem tentar perseguir, por meio de exemplos de perseverança, fé e entrega pastoral:

Entrou uma professora na escola que eu digo assim, que é a minha idola. Quando eu crescer eu quero ser que nem ela. Já é uma senhora aposentada, ela está com uma quarta série, então foram meus na terceira, eram terríveis. Ela pegou essa turma agora na quarta, ela não faz um comentário negativo sobre as crianças. Eu acho isso assim uma coisa fabulosa. Então eu digo assim que eu estou aprendendo muito com ela. (Professora S)

Paulatinamente os dispositivos de controle vão construindo e reconstruindo um perfil de docência que se aproxima muito de um modelo de dedicação pastoral, reforçado por docentes mais antigos que, por sua experiência e dedicação, "deram certo" na carreira e, hoje, amam aquilo que fazem, apesar das adversidades reconhecidas e descritas como "nadar contra a maré".

Os exemplos de dedicação ou de impotência contra o já estabelecido favorecem formas de padronização dos saberes docentes, e assim multiplicam-se estratégias para impedir conflitos entre as rotinas consagradas na escola e aquilo que as professoras em início de carreira podem vir a propor. Para evitar crises apela-se à padronização das práticas 
pedagógicas, evitando o risco da diversidade do trabalho educativo, que poderia produzir novas formas culturais de contestação - ou dar mais trabalho às professoras mais antigas:

(...) às vezes, geralmente porque de repente tu fazes uma coisa e tu apareces e ela não; às vezes tu vais fazer dá muito trabalho e eu não estou a fim. Ano passado eu levei as crianças no teatro: "gente vamos levar as crianças no teatro?". Tem uma proposta de levar na quarta-feira, que as crianças não pagam. "Ah, ah, ah, vamos levar no teatro!" Me fechei, conversei com a direção, consegui o ônibus e fui para o teatro com as crianças. Nossa senhora! (risos). Como que eu fiz isso? Que audácia! (mais risos). Não, foi uma colega, uma colega específica, ficou muito indignada: "como eu levei as crianças ao teatro, como é que eu consegui?". Quando eu cheguei e disse foi uma gargalhada. Tá, fiquei quieta, nem vou falar mais nada. (Professora $S$ )

Contra as iniciativas pedagógicas das professoras em início de carreira, os dispositivos fazem valer o peso da experiência das docentes mais antigas, seus discursos críticos sobre novas iniciativas que, de forma geral, acabam impedindo inovações no saber-fazer pedagógico da escola, multiplicando estratégias cada vez mais apuradas de controle sobre o conhecimento escolar e curricular; tratando de incorporar mecanismos de vigilância ao próprio processo de trabalho, para que o controle externo se transmute em autocontrole. A fala de uma professora a seguir, apesar de longa, é uma passagem muito ilustrativa disso:

No ano passado eu trabalhei em uma outra escola com alfabetização e foi uma experiência muito trágica. (...) eu tive vários problemas: problemas com a direção, com os pais, com todo mundo que eu podia ter, menos com os alunos. (...) naquele momento estava me construindo um pouco como alfabetizadora, isso era novo para mim, então eu estava tentando construir como que eu poderia fazer isso, cheia de receios, de medos, de angústias e neuroses também, e não foi aceito, não foi aceito de forma nenhuma, porque tinha duas professoras que alfabetizavam pelo método fonético e eu não. Eu comecei apresentando, de forma geral, o ambiente letrado, trabalhando com tudo muito junto e isso para os pais foi um horror. Só que daí o que eu esperava, eu conversava com os pais, os pais se acalmavam (...). Só que... o que acontecia? Eles iam falar com a direção e a direção também não gostava daquilo; (...) a direção tinha medo, elas achavam que as crianças não iam se alfabetizar (...). Então não reforçava o [meu] trabalho e isso foi criando um conflito. Então eu acho 
que desde o início, desde março, quando peguei a turma, até junho, acho que eu chorava todos os dias, menos sábado e domingo, quando eu chegava em casa (...). Os pais reclamavam, a direção comparava com outra professora, pegavam o caderno da outra série para mostrar, para comparar e foi muito tenso. Aí a direção da escola, por duas ou três vezes, me chamou para uma reunião, foi muito estranho, eu nunca tinha vivenciado isso. Lá por março, abril, me chamaram na secretaria, daí eram duas supervisoras, uma diretora e a secretária, e era para dizer que aquele trabalho não estava sendo aceito na escola, que os pais não estavam entendendo (...). Aí eu conversei com elas, que eu achava que não, que tinha uma outra perspectiva de alfabetizar, não queria dizer que tinha só uma forma de alfabetizar, havia outras que a gente tinha que valorizar, e eu, ao mesmo tempo em que afirmava essa forma de trabalho, também tinha muita insegurança. (...) Depois que elas me chamaram para essa reunião fiz reunião com os pais, eles se acalmaram um pouquinho, mas também estavam inseguros. Daí elas me chamaram para uma segunda reunião, depois de uns 15 ou 20 dias os pais não viam coisas no caderno das crianças, queriam ver letras, coisas escritas (...). Aí me chamaram para uma outra reunião, pedindo para eu mudar o meu trabalho e eu disse que não. Me chamaram para outra reunião com uma ata que elas queriam que eu assinasse, com ata pronta. $\mathrm{Na}$ ata dizia que a direção chamou a professora "fulana de tal" para outra conversa, para mudar a metodologia de trabalho; a professora não mudou (...) e que agora a escola exigia ou solicitava que a professora mudasse a metodologia de trabalho, começasse a trabalhar conforme o alfabeto... (...) Fiquei furiosa, não assinei a ata, disse que não ia assinar, que queria uma reunião com a Secretaria Municipal de Educação (SME), porque a SME, (...) em todos os eventos que a SME propiciava, trabalhava numa perspectiva de alfabetização que não era essa perspectiva convencional, o método da sequência, fonético. Aí chamaram a SME, eu achando que eu ia me dar bem, achando que elas trabalhavam teoricamente nessa perspectiva (...). Me chamaram para outra reunião, as duas coordenadoras, a diretora e a secretária, contaram tudo isso, eu contei a minha parte, e nisso eu feliz porque a minha expectativa era que a SME ia me apoiar, dar respaldo para o meu trabalho. Não, a SME ficou meio em cima do muro, "tu podes mudar algumas coisas". Não fiquei muito feliz, porque o que eu queria na realidade era que me dessem um apoio, falaram isso a vida toda, não me deram (...), ficaram de vir um outro dia. Daí todo mundo: "a professora A tem reunião com a SME às 5:30h”. Aí veio uma criatura, porque daí ela ia olhar o meu trabalho (...), então ela queria olhar o planejamento. Juntei todo o meu material e mostrei e a SME, muito querida, disse que estava tudo muito bem, mas que eu tinha que clarear algumas coisas, e disse que ia vir na outra semana. Nunca mais veio, nunca mais apareceu. (Professora A) 
A professora encontrou-se sozinha e individualmente responsabilizada pelo sucesso ou fracasso de seus alunos. De alguma forma, seu futuro e carreira começam a ser restringidos aos resultados que poderiam obter seus alunos e alunas. A transferência de responsabilidade para a professora constituiu-se num potente dispositivo de controle que funcionou, paulatinamente, para seu enquadramento na tradição da escola. $\mathrm{O}$ controle assentado na tradição funcionou então como um mito que dá um significado à profissão docente. Parodiando Bourdieu (1998), podemos dizer que o discurso funciona por toda parte, o dia todo. Não há o que opor a ele. Há todo um trabalho de doutrinação simbólica do qual participam ativamente as lideranças da escola e seus profissionais mais antigos, ${ }^{4}$ bem como os órgãos de coordenação do ensino.

Constitui-se assim outra dimensão do controle na qual são combinados aspectos aparentemente discrepantes. Importa que nessa combinação sejam produzidos os discursos legítimos e as autoridades legítimas - quem pode falar e quem não pode; o que deve ser dito e o que não deve.

Esse poder cria uma prática educativa suturada a uma rede de controle mais ampla e que, no entanto, faz uso de estratégias que parecem dar segurança (informação) às professoras sobre a qualidade do seu trabalho. Com efeito, o controle passa a ser, em alguma medida, desejado pelas próprias professoras. Um controle que apela à tradição da escola, de sua direção, das professoras mais antigas, acionado por dispositivos que se pretendem mais democráticos e mais fraternos, baseados na experiência já encontrada nas escolas e que deve ser seguida para a manutenção da coesão do grupo docente (Vieira, 2004).

Vale destacar que a tradição é aqui compreendida como herança cultural, legado de crenças transmitidas. A ideia de transmissão ou de entrega de fatos, lendas, ritos, usos, costumes busca produzir certa coesão moral no corpo social. Seu caráter quase sempre doutrinal ou dogmático, proferido pelo mais antigo ou pela autoridade, procura garantir a continuidade das experiências já vividas, funcionando como uma espécie de eco, perpetuando hábitos e costumes adquiridos e tornados rotina. Numa palavra: naturalizados.

Dessa forma, a tradição busca garantir aquilo que imagina ser a pureza inicial ou anterior "e recobrir as unidades e certezas que são sentidas como tendo sido perdidas” (Hall, 2001, p. 87). A tradição então 
Dispositivos de regulação conservadora, currículo e trabalho docente

funciona para a conservação de uma cultura imaginada. Seus apelos ou suas estórias preferidas produzem as balizas por onde devem navegar os significados, as práticas e os discursos do grupo social.

No caso da escola, seus dispositivos de controle funcionam para preservar uma suposta natureza educacional - seja da perspectiva do indivíduo (sua psicologia e sua ontologia), seja da perspectiva institucional (sua história e suas relações sociais) - no interior da representação legitimada, impedindo e/ou negando que outras práticas de formação ou transformação habitem o processo educativo. No mínimo, retardando sua eficácia.

Os dispositivos de controle conservadores agem para constituir e perpetuar significados que têm efeitos na produção de sentidos, formando um sistema de representação cultural que legitima uma ideia de escola tal como é definida pela tradição e pelos discursos das políticas curriculares e educativas.

Dessa forma, o trabalho docente somente pode existir em uma comunidade simbólica constituída pela tradição, garantido pela instituição e por seus ritos, hábitos e costumes "originários", gerando, como escreve Hall (citando Schwarz, 2001, p. 49), um "sentimento de identidade e lealdade” à instituição que, neste caso, transmuta-se na própria tradição.

Por mais paradoxal que possa parecer, os dispositivos de controle que apelam para a tradição não podem deixar de sofisticar suas estratégias de disciplinarização do professorado. Por mais que os processos de recontextualização sejam singulares e possam desencadear hibridismos, a força da tradição busca impor um sentido a essas políticas curriculares, uma coerência (Bernstein, 1996; Ball, 2001; Lopes, 2005).

Uma das novas estratégias de controle sobre o processo de trabalho docente tem ocorrido, por exemplo, por intermédio da publicização dos resultados alcançados por cada docente com seus alunos e alunas, em testes, estatísticas de aprovação/reprovação, comparação entre escolas, notas, pesquisas de opinião, bonificaçôes, atividades de sucesso ou de fracasso, entre outras. ${ }^{5}$ A educação é então integrada numa rede de regulação social que visa legitimar o controle sobre o trabalho docente (Vieira, 2004).

A rede de regulação social estabelece-se como um poderoso e benéfico auxílio ao trabalho docente, geralmente de caráter pastoral. A professora é levada a acreditar que a experiência das colegas mais antigas lhe fornece um quadro mais seguro sobre como desenvolver seu 
trabalho. Dessa forma, o controle transforma o trabalho docente num compromisso de responsabilidade individual absoluta, e todos são convocados a uma "missão quase-sagrada" de educar as novas gerações sem alterar significativamente as relaçóes de poder nas escolas.

(...) aquela escola parece que tem uma diferença, parece que ela está meio esquecida. Ali cada um faz o que quer, do jeito que quer, a coisa está meio solta, até há reclamação de alguns professores, não tem uma coordenadora que se reúna com os professores, não tem plano de aula. Há quatro anos a escola reabriu e os professores simplesmente não têm o plano de aula. Então é tudo solto, eles fazem o que querem. Então os professores que entraram agora discordam. Eu [e] uma outra colega discordamos, porque eu acho que tem um programa, tem um conteúdo, tem que seguir aquele programa, até porque um é pré-requisito de outro. $\mathrm{O}$ aluno precisa desenvolver algumas coisas na primeira para depois desenvolver na segunda e assim vai. E isso fica solto, não é rígido, não tem uma coordenadora que peça isso, até no início eu perguntei: "até que data eu tenho que entregar meu planejamento?”. Até a SME pediu que se colocasse a história dos negros africanos, e eu não senti que elas tinham vontade de trabalhar, de olhar, de revisar plano de aula, não... uma coisa muito esquecida. (Professora T)

A aparente flexibilidade é efetivamente restrita à sala de aula, permitindo uma miragem de autonomia, que acaba integrando a conduta das professoras à disciplina desejada pela escola. Isso institui o currículo e o processo de trabalho docente como campos de controle sobre o professorado, no sentido de torná-lo operativo às demandas que lhes são estranhas.

Se combinarmos essas formas de controle com a atual onda da cultura avaliativa, podemos entender quão normalizado vem sendo o professorado pela crescente regulação do seu processo de trabalho, por meio de dispositivos culturais, discursivos, políticos e curriculares.

Nessa direção, nossa investigação das formas específicas de produção desses dispositivos de controle faz ver que, em grande medida, as decisões curriculares no processo de trabalho docente já estão circunscritas à tradição.

\section{Conclusão}

A análise que vimos realizando faz ver que, no discurso das professoras, os contextos escolares apresentam realidades muito semelhantes, 
que podem ser sintetizadas na precariedade das condições de trabalho tanto em relação à infraestrutura física quanto ao apoio didático-pedagógico.

Acreditamos que os efeitos dessa precariedade direcionam o olhar da professora tanto para uma visão negativa da cultura dos estudantes quanto para o favorecimento da ação de dispositivos de controle sobre seu processo de trabalho. No primeiro caso, os alunos e as alunas são construídos em função de um possível "déficit" social e cultural, que deve ser compensado por meio de um trabalho feito com perseverança, criatividade e dedicação pastoral por parte da docente, em geral seguindo as práticas já instaladas na escola pelas professoras mais antigas. Aqui se exige da professora uma observância às normas - à tradição - da escola e uma enorme tolerância com os ritmos e ritos escolares ali instalados. Acatar o que já está posto na escola é, de toda sorte, uma garantia da aceitação da professora por parte do grupo de docentes. No segundo caso, diretamente relacionado ao primeiro efeito, a professora acaba sendo submetida aos dispositivos de controle pela própria insegurança, pela impotência e pelo isolamento que experimenta perante a realidade que encontra na escola. Exemplo típico que reforça isso é o caso relatado por uma das professoras sobre uma colega que chega e sai da escola somente com sua bolsa, sem muitas preocupaçóes com o que acontece em sua sala de aula ou mesmo no dia-a-dia da escola.

Em geral não existe um apoio pedagógico sistemático para a professora em início de carreira, restando-lhe somente apoios e informações ocasionais e exemplares das colegas mais antigas. Entretanto, as respostas das professoras aos dispositivos de controle não são homogêneas nem podem ser vistas apenas de forma passiva:

(...) esse grupo que eu comecei a participar [fora da escola] era um grupo de troca, a gente levava material, selecionava coisas e nos reuníamos uma vez por semana para trocar material, socializar o que cada uma tinha feito, se dava para fazer, se não dava, se cabia para minha turma, se não cabia. Nós éramos mais de uma pessoa com a primeira série, muitos problemas da sala de aula, com o cotidiano da escola (...). Mais experiência [era trocada] que material. (...) cada uma de nós tinha problemas diferentes, umas tinham problema de violência, então para nós conseguirmos [nos ajudar], a gente sugeria soluçóes para aquela pessoa (...); era um espaço de troca e construção, todas nós queríamos qualificar o nosso trabalho e a gente buscava naquele grupo esse espaço para fazer isso. (Professora A) 
Mesmo considerando que os dispositivos buscam a conformabilidade das professoras recém-chegadas à escola, existem pontos de fuga produzidos por aquilo que pode, provisoriamente, ser denominado de inconformabilidade ante a tradição. Contudo, a professora, quando não tem respaldo da escola ou da Secretaria de Educação, pode reagir ao discurso veiculado pelos dispositivos de controle, criando algo como um contracontrole, buscando respostas e apoios diante da ação dos dispositivos. Assim, essas saídas podem ser individuais e fomentadas para o individualismo, formas mais fragmentadas e balcanizadas, outras vezes podem buscar formas mais coletivas e colegiadas de organização, como os modelos de práticas colaborativas, tal como assinala Hargreaves (1994). O que importa destacar é que não há garantias; mesmo essas formas alternativas de organização do trabalho podem ser colonizadas.

O que se pode ver neste artigo é que as docentes em início de carreira se encontram fortemente expostas a discursos conservadores, que buscam conformá-las aos modelos curriculares e colonizá-las por dispositivos de controle que pressionam para o caminho da tradição, seja por práticas discursivas controladoras, seja por práticas curriculares que dão certo, seja, ainda, por práticas docentes tidas como amorosas, dedicadas e efetivas. O que importa é que a inexperiência e a insegurança presentes na professora em início de carreira sejam capturadas pela tradição curricular e educativa.

\section{Recebido em dezembro de 2007 e aprovado em outubro de 2008.}

\section{Notas}

1. Projeto de pesquisa intitulado "Controle através da tradição: dispositivos de regulação conservadora das escolas sobre o processo de trabalho docente", financiado pelo CNPq (2005/ 2006).

2. Sempre que nos referirmos às pessoas entrevistadas o substantivo será posto no feminino.

3. Tivemos já oportunidade de discutir esses aspectos em outros trabalhos (Hypolito, 1997; Vieira, 1992), assim como pretendemos ter chance de discuti-los em outro artigo, em preparação.

4. Vide passagem anterior relatada pela professora $S$, sobre o convite que fez aos seus colegas para irem ao teatro, quando recebeu uma gargalhada como resposta.

5. Por exemplo, entre muitos possíveis, o caso de duas escolas gaúchas que receberam, no dia 16 de março de 2006, no Ministério da Educação, em Brasília, R\$ 140 mil referentes ao 
Dispositivos de regulação conservadora, currículo e trabalho docente

Prêmio Melhoria do Ensino Médio Noturno. Ver notícia no site da SEE/Rs. Disponível em: $<$ http://www.educacao.rs.gov.br/pse/html/educa_not_det.jsp?ID $=1815 \& q t d=0 \& i n i=$ $0 \&$ ir $=$ T\&tot $=0>$. Acesso em: 15 mar. 2006.

\section{Referências}

BALL, S.J. Diretrizes políticas globais e relações políticas locais em educação. Curriculo sem Fronteiras, v. 1, n. 2, p. 99-116, jul./dez. 2001.

BARDIN, L. Análise de conteúdo. Lisboa: Edições 70, 1997.

BERNSTEIN, B. A estruturação do discurso pedagógico: classe, códigos e controle. Petrópolis: Vozes, 1996.

BOURDIEU, P. Contrafogos: táticas para enfrentar a invasão neoliberal. Rio de Janeiro: Zahar, 1998.

DELEUZE, G. ¿Que és un dispositivo? In: Balbier, E. et al. Michel Foucault, filósofo. Barcelona: Gedisa, 1990. p. 155-161.

FOUCAULT, M. Vigiar e punir: nascimento da prisão. Petrópolis: Vozes, 1977.

FOUCAULT, M. Microfísica do poder. 5. ed. Rio de Janeiro: Graal, 1985.

FOUCAULT, M. História da sexualidade I: a vontade de saber. 11. ed. Rio de Janeiro: Graal, 1988.

GARCIA, M.M.A. Pedagogias criticas e subjetivação: uma perspectiva foucaultiana. Petrópolis: Vozes, 2002.

GARCIA, M.M.A.; HYPOLITO, A.M.; VIEIRA, J.S. (Org.). As identidades docentes como fabricação da docência. Educação \& Pesquisa, São Paulo, v. 31, n. 1, p. 45-56, jan./abr. 2005.

GOODSON, I.F. Currículo: teoria e história. Petrópolis: Vozes, 1995.

GORDON, C. Racionalidade governamental: uma introdução. In: Burchell, G.; Gordon, C.; Miller, P. (Ed.). The Foucault effect studies in governmentality. Chicago: University of Chicago, 1991.

HALL, S. A identidade cultural na pós-modernidade. 3. ed. Rio de Janeiro: DP\&A, 2001. 
HARGREAVES, A. Os professores em tempos de mudança. Lisboa: McGraw-Hill, 1994.

HYPOLITO, A.M. Trabalho docente, classe social e relaçôes de gênero. Campinas: Papirus, 1997. v. 1.

HYPOLITO, A.M.; GARCIA, M.M.A.; VIEIRA, J.S. (Org.). Trabalho docente: formação e identidades. Pelotas: Seiva, 2002.

LARROSA, J. Escuela, poder y subjetivación. Madrid: La Piqueta, 1995.

LOPES, A.C. Política de currículo: recontextualização e hibridismo. Currículo sem Fronteiras, v. 5, n. 2, p. 50-64, jul./dez. 2005.

SILVA. T.T. Currículo e identidade social: territórios contestados. In: Silva, T.T. (Org.). Alienígenas na sala de aula: uma introdução aos estudos culturais em educação. Petrópolis: Vozes, 1995.

SILVA, T.T. Documentos de identidade: uma introdução às teorias do currículo. 2. ed. Belo Horizonte: Autêntica, 1999.

VEIGA-NETO, A. Governo ou governamento. Currículo sem Fronteiras, v. 5, n. 2, p. 79-85, jul./dez. 2005.

VIEIRA, J.S. Limites da racionalização do processo de trabalho escolar: contradiçóes e práticas do trabalho docente. Porto Alegre: FACED; UFRGS, 1992.

VIEIRA, J.S. Um negócio chamado educação: qualidade total, trabalho docente e identidade. Pelotas: Seiva, 2004.

VIEIRA, J.S.; SANDER, D.A. Temas transversais: estudo sobre as representações e as práticas de significação nos currículos escolares do ensino fundamental. (Relatório de pesquisa. Pelotas: FAE/UFPEL - CNPq, 2003).

VIEIRA, J.S.; HYPOLITO, A.M.; DUARTE, B.G.V. Controle através da tradição: dispositivos de regulação conservadora, currículo e trabalho docentes. In: REUNIÃO ANUAL DA ANPEd, 29., 2006, Caxambú. Anais... Caxambú: ANped, 2006.

VIEIRA, J.S.; HYPOLITO, A.M.; DUARTE, B.G.V. Controle através da tradição: dispositivos de regulação conservadora, currículo e trabalho docentes. (Relatório de pesquisa. Pelotas: FAE/UfPEL - CNPq, 2007). 